\title{
Behandlingssvikt ved osteosyntese av lårhalsbrudd
}

Engelsk oversettelse på www.tidsskriftet.no

\begin{abstract}
Sammendrag
Bakgrunn. Behandlingen av lårhalsbrudd domineres av to typer inngrep: osteosyntese og protesekirurgi. En av ulempene ved osteosyntese er at mange av pasientene senere får behov for en ny operasjon. Vi har forsøkt å identifisere behandlingsrelaterte faktorer som øker risikoen for osteosyntesesvikt.
\end{abstract}

Materiale og metode. Journal og røntgenbilder til 337 pasienter behandlet med lukket reposisjon og osteosyntese for mediale lårhalsbrudd ved Oslo universitetssykehus, Aker i perioden 1999-2000 ble gjennomgått retrospektivt. Kvaliteten på reposisjonen av bruddet og plasseringen av osteosyntesematerialet ble vurdert på en skala der det ble gitt maksimalt 6 poeng ved beste resultat.

Resultater. Hos pasienter med dislokerte brudd sviktet osteosyntesen hos $23(18,3 \%)$ av 126 pasienter som fikk utført en reposisjon gitt 6 poeng. Hos pasienter som fikk utført en reposisjon gitt 3 eller færre poeng, sviktet osteosyntesen hos fem $(50,0 \%)$ av ti $(p=0,017)$. Vi fant dessuten $ø$ kt risiko for manglende tilheling hos pasienter med dislokerte brudd operert mer enn 48 timer etter skadetidspunktet. I denne gruppen opptrådte manglende tilheling hos fem ( $25 \%$ ) av 20 pasienter sammenliknet med $16(8,0 \%)$ av 200 pasienter operert innen 48 timer ( $p=0,014)$.

Fortolkning. Ved osteosyntese av lårhalsbrudd med feilstilling bør man oppnå anatomisk reposisjon av bruddet, og operasjonen bør utføres innen 48 timer med mindre det foreligger medisinske kontraindikasjoner.

Artikkelen er basert på en studentoppgave levert ved det medisinske fakultet,

Universitetet i Oslo (1).
Sigurd Erik Hoelsbrekken*

s.e.hoelsbrekken@medisin.uio.no Jan-Henrik Opsahl*

Ortopedisk avdeling

Morten Stiris*

Radiologisk avdeling

\section{Øyvind Paulsrud*}

Knut Strømsøe

Ortopedisk avdeling

Oslo universitetssykehus, Aker

* Nåværende adresser:

Sigurd Erik Hoelsbrekken, Ortopedisk avdeling

Akershus universitetssykehus

Jan-Henrik Opsahl, Radiologisk avdeling Sykehuset Telemark

Morten Stiris, Unilabs Røntgen Bryn

Øyvind Paulsrud, Ortopedisk avdeling

Oslo universitetssykehus, Ullevål

Norge er et av landene med høyest forekomst av hoftebrudd, og i Nasjonalt hoftebruddregister ble det i 2009 registrert rundt 5000 primæroperasjoner som følge av lårhalsbrudd (2). Lårhalsbruddene kan deles inn i to grupper: brudd uten særlig feilstilling (udislokerte brudd) og brudd med feilstilling (dislokerte brudd).

Lårhalsbrudd behandles med osteosyntese eller ved innsetting av en hofteprotese (artroplastikk). Ved osteosyntese utføres det i de fleste tilfeller en lukket reposisjon, og bruddet fikseres internt med skruer eller nagler. En av ulempene ved denne behandlingen er at mange av pasientene senere får behov for en ny operasjon, og risikoen er størst for pasientene med dislokerte brudd $(3,4)$. Den hyppigste årsaken til reoperasjon er osteosyntesesvikt med sekundær dislokasjon av bruddet, deretter følger manglende tilheling og nekrose av lårbeinshodet (5). Klinisk medfører de to siste fenomenene manglende fremgang i mobiliseringen av pasienten og vedvarende smerter i lysken. De fleste av pasientene med en svikt av osteosyntesen får satt inn en protese sekundært.

Tall hentet fra Nasjonalt hoftebruddregister viser at et flertall av de udislokerte, og i underkant av $20 \%$ av de dislokerte lårhalsbruddene i 2009 ble behandlet med osteosyntese (2). Årsrapportene fra Hoftebruddregisteret viser dessuten at trenden går i retning av å utføre flere artroplastikker. Unge pasienter står imidlertid i en særstilling. Hos disse pasientene vil man ofte forsøke å bevare hofteleddet ved å utføre en osteosyntese.

Vi har forsøkt å identifisere behandlings- relaterte faktorer som øker risikoen for osteosyntesesvikt ved lukket reposisjon og osteosyntese av lårhalsbrudd. Kunnskap om slike faktorer vil kunne redusere antall reoperasjoner og dermed gi pasientene man velger å behandle med osteosyntese en bedre prognose.

\section{Materiale og metode \\ Utvelging av pasienter}

Pasienter behandlet for mediale lårhalsbrudd med osteosyntese i perioden 1.1. 1999-31.12. 2000 ved Ortopedisk avdeling, Oslo universitetssykehus, Aker ble identifisert ved hjelp av sykehusets eget hendelsesregister. Pasienter med maligne sykdommer, amputasjoner av underekstremitetene og pasienter som pådro seg nye brudd i underekstremitetene i løpet av de første tre månedene etter lårhalsbruddet ble ekskludert fra studien.

\section{Oppfølging}

Samtlige pasienter ble innkalt til kontroll etter tre måneder. Kontroll etter dette ble utført hvis forholdene ikke var tilfredsstillende ved kontrollen etter tre måneder eller ved henvendelse fra pasienten selv, pårørende eller fastlege. Slike henvendelser kom hovedsakelig som følge av vedvarende smerter og redusert gangfunksjon.

\section{Datainnsamling}

Alle journaldokumenter og røntgenbilder de første fem årene etter bruddet ble gjennomgått. Vurdering av de enkelte røntgenbildene med hensyn til Gardens klassifikasjon (6), årsak til osteosyntesesvikt, kvalitet på reposisjonen og plassering av osteosyntesematerialet ble utført i fellesskap av en assistentlege under spesialisering i ortopedisk kirurgi og en overlege med spesialitet i ortopedisk kirurgi. Samme assistentlege og to ulike

\section{Hovedbudskap}

- Pasienter behandlet med lukket reposisjon og osteosyntese for lårhalsbrudd har stor risiko for osteosyntesesvikt

- Mangelfull reposisjon medfører økt risiko for osteosyntesesvikt ved intern fiksasjon av mediale lårhalsbrudd med feilstilling

- Operasjon mer enn 48 timer etter skadetidspunktet gir økt risiko for osteosyntesesvikt ved intern fiksasjon av mediale lårhalsbrudd med feilstilling 


\section{Ramme 1}

Røntgenkriterier for bedømmelse av reposisjonen av bruddet (a) og plasseringen av osteosyntesematerialet (b) (7)

\author{
a. Reposisjon av bruddet \\ Frontalbilde: \\ - Ingen varusstilling eller maksimalt $15^{\circ}$ \\ valgusstilling \\ - Maksimalt $2 \mathrm{~mm}$ dislokasjon \\ Sidebilde: \\ - Maksimalt $20^{\circ}$ ventral eller $10^{\circ}$ dorsal \\ feilstilling \\ - Maksimalt $2 \mathrm{~mm}$ dislokasjon
}

3 poeng: alle kriterier er tilfredsstilt 2 poeng: ett kriterium er ikke tilfredsstilt 1 poeng: to kriterier er ikke tilfredsstilt Det gis poeng både for frontal- og sidebilde. Maksimal poengsum er $3+3=6$ poeng.

b. Plasseringen av osteosyntesematerialet Frontalbilde:

- Kaudale nagle skal ligge langs calcar

- Avstanden mellom naglene skal være så stor som anatomien tillater

- Begge nagler skal være parallelle med lårhalsen

- Begge nagler skal ligge subkondralt med maksimalt $5 \mathrm{~mm}$ avstand til brusk Sidebilde:

- Ingen av naglene skal ligge i fremre tredel av caput. Det trekkes fra 1 poeng for hver nagle plassert i fremre tredel.

3 poeng: alle kriterier er tilfredsstilt 2 poeng: ett kriterium er ikke tilfredsstilt 1 poeng: to eller flere kriterier er ikke tilfredsstilt

Det gis poeng både for frontal- og sidebilde. Maksimal poengsum er $3+3=6$ poeng.

overleger deltok ved disse vurderingene. Ved uenighet ble det aktuelle røntgenbildet vurdert av alle tre. Bruddene ble delt inn i udislokerte (Garden I-II) og dislokerte (Garden III-IV). Det er viktig å understreke at ved Gardens klassifikasjon vurderes stillingen av lårhalsbruddet kun i frontalplanet slik at brudd betegnet som udislokerte også reponeres. Opplysninger om dødstidspunkt ble innhentet fra folkeregisteret. Innsamling og bearbeiding av person- og helseopplysninger for bruk i studien ble tilrådt av personvernombudet, Oslo universitetssykehus.

\section{Analyse}

Fiksasjonssvikt, manglende tilheling og caputnekrose ble valgt som endepunkter. Et lårhalsbrudd vil normalt kunne tilhele hvis det ikke tilkommer sekundær dislokasjon i løpet av de første tre månedene etter operasjonen (7). Vi definerte derfor fiksasjonssvikt som radiologisk bedømt svikt av osteofiksasjonen og dislokasjon av bruddet i løpet av de første tre månedene. Synlig fraktur- spalte etter tre måneder til tross for god stilling av bruddet og godt leie av osteosyntesematerialet definerte vi som manglende tilheling. Ved caputnekrose tilkom det et avaskulært betinget sammenfall av lårbeinshodet. Vi har valgt å bruke begrepet osteosyntesesvikt som en samlebetegnelse for fiksasjonssvikt, manglende tilheling og caputnekrose da disse tre tilstandene utgjør hovedårsakene til behov for en ny operasjon.

Kvaliteten på reposisjonen og plasseringen av osteosyntesematerialet ble registrert som årsaksfaktorer. I tillegg så vi på om operasjonstidspunktet hadde betydning for utfallet. Kriteriene som ble lagt til grunn for bedømmelsen av kvaliteten på reposisjonen og plasseringen av osteosyntesematerialet er gjengitt i ramme 1 (7). Disse er basert på kriterier som i et tidligere arbeid ble funnet å ha prognostisk betydning for utfallet (8).

For å beregne interobservatør-reliabilitet brukte vi Fleiss' kappa for multiple observatører. Verdien kan deles inn i: ingen korrelasjon $(0,00-0,20)$, svak $(0,21-0,40)$, moderat $(0,41-0,60)$, god $(0,61-0,80)$ og svært god $(0,81-1,00)$. Kappaverdien ble regnet ut mellom de samme tre legene som også vurderte røntgenbildene inkludert i dette arbeidet, og er basert på 50 anonymiserte, tilfeldig utvalgte røntgenbilder bedømt i tilfeldig rekkefølge. Ingen av disse 50 bildene ble inkludert i studien.

\section{Statistiske metoder}

Ved bivariate analyser brukte vi Pearsons khikvadrattest med krysstabell. Logistisk regresjon for dikotome utfall ble utført ved multivariate analyser. Overlevelsesanalyser ble utført etter Kaplan-Meiers metode.

\section{Resultater}

Totalt ble 385 pasienter vurdert for inklusjon i studien. 16 pasienter manglet dokumentasjon $\mathrm{i}$ form av journalopplysninger eller røntgenbilder og 32 pasienter tilfredsstilte ikke inklusjonskriteriene. Garden klassifisering og alders- og kjønnssammensetning til de 337 pasientene som ble tatt med i studien er gjengitt i tabell 1 . Av pasientene som ble inkludert møtte 250 (74,2\%) opp til tremånederskontroll. $94(27,9 \%)$ av pasientene ble fulgt opp etter denne kontrollen.

Kun 17 av de 117 pasientene med udislokerte brudd ble gitt mindre enn 6 poeng for reposisjonen av bruddet. Osteosyntesen sviktet hos bare en av disse pasientene (tab 2). Vi fant dermed ingen økt risiko for osteosyntesesvikt hos pasienter med udislokerte brudd som ble gitt en lavere poengsum for reposisjonen. Dette var i kontrast til pasientene med dislokerte brudd hvor andelen osteosyntesesvikt var signifikant høyere hos pasientene som ble gitt en dårligere poengsum (tab 2). Reposisjonskriteriene hadde en interobservatør kappaverdi (95\% konfidensintervall $(\mathrm{KI}))$ på $0,50(0,39-0,61)$. Kappaverdien økte imidlertid til $0,70 \mathrm{hvis}$ vi delte kvaliteten på reposisjonen inn i følgende tre grupper: til- fredsstillende (6-5 poeng), lite tilfredsstillende (4-3 poeng) og ikke tilfredsstillende (2 poeng).

Vi observerte ingen signifikant innflytelse på utfallet av osteosyntesen med hensyn til naglenes plassering (tab 3), og det ble heller ikke avdekket noen signifikant innflytelse hvis vi justerte for kvaliteten på reposisjonen og tidspunktet for operasjonen ved logistisk regresjon. Kriteriene for naglenes plassering hadde en kappaverdi $(95 \% \mathrm{KI})$ på $0,42(0,34-0,51)$.

Operasjon mer enn 48 timer etter skadetidspunktet hos pasienter med udislokerte brudd medførte ingen økt risiko for osteosyntesesvikt (tab 4), men det er viktig å understreke at pasientantallet var for lavt til å avdekke eventuelle små forskjeller.Hos pasienter med dislokerte brudd var imidlertid andelen osteosyntesesvikt høyere i pasientgruppen som ble operert mer enn 48 timer etter skadetidspunktet.Manglende tilheling utgjorde den hyppigste årsaken til svikt i denne gruppen, og andelen var signifikant høyere sammenliknet med andelen hos pasienter operert innen 48 timer (tab 4). Erfaringsmessig kan eldre brudd være vanskeligere å få reponert til god stilling, men regresjonsanalyser som justerte for kvaliteten på reposisjonen medførte ingen signifikante endringer.

Mortaliteten var lik hos pasienter operert innen 48 timer sammenliknet med pasienter operert etter 48 timer. Det var heller ingen forskjell i mortalitet hos pasienter gitt en høyere poengsum for reposisjonen sammenliknet med pasienter gitt en lavere sum. Gruppen som hadde lavest mortalitet var pasienter som fikk konstatert en osteosyntesesvikt.

Disse pasientene hadde en treårsoverlevelse på $66 \%$ sammenlignet med $52 \%$ hos pasientene uten svikt ( $\mathrm{p}=0,015)$ (fig 1).

\section{Diskusjon}

Osteosyntese av lårhalsbrudd har tradisjonelt vært forbundet med stor risiko for behandlingssvikt. I vårt materiale var andelen osteosyntesesvikt lav sammenliknet med andre studier hvor andelen har ligget på $8-24 \%$ og $35-62 \%$ ved respektivt udislokerte og dislokerte brudd (8-11). Årsakene til dette kan være mange. Kun et mindretall av pasientene ble fulgt opp etter tre måneder, slik at ikke alle tilfellene av osteosyntesesvikt ble fanget opp. I tillegg ble sannsynligvis noen av pasientene behandlet ved andre sykehus uten at det ble registrert $i$ vårt materiale. Hvis pasientene hadde vært fulgt prospektivt, ville antallet registrerte tilfeller av osteosyntesesvikt sannsynligvis vært høyere. Imidlertid er det liten grunn til å tro at de uregistrerte tilfellene fordelte seg så skjevt at det hadde signifikant innflytelse på sammenlikningen av risikoen for osteosyntesesvikt mellom de ulike pasientgruppene.

Vi fant ingen sammenheng mellom risikoen for osteosyntesesvikt og kvaliteten på reposi- 
sjonen hos pasienter med udislokerte brudd. Dette var ikke uventet siden reposisjonsresultatene var mer ensartet, og risikoen for osteosyntesesvikt betydelig lavere, sammenliknet med dislokerte brudd. Samtidig er det viktig å understreke at mange udislokerte brudd er innkilte og har en høy grad av egenstabilitet. Slike innkilte brudd har en god prognose og bør fikseres uten forsøk på reposisjon. Når det gjaldt dislokerte brudd, fant vi en høyere risiko for osteosyntesesvikt hos pasienter som fikk utført en dårligere reposisjon, noe som er i tråd med tidligere arbeider $(8,12,13)$.

Det har vært gjort en rekke forsøk på å etablere radiologiske kriterier som har prognostisk betydning for utfallet hos pasienter behandlet med osteosyntese (14-17). I hovedsak har man vært opptatt av preoperative faktorer, og interobservatør-reliabiliteten har vært $0,20-0,58$ (18-20). I vårt materiale oppnådde vi en kappaverdi på 0,50 for reposisjonskriteriene, noe som til sammenlikning er akseptabelt.

Vi fant ingen signifikant innflytelse av naglenes plassering på risikoen for osteosyntesesvikt. Dette kan skyldes at kriteriene vi valgte ikke har betydning for prognosen, eller at antall pasienter var for lavt til å avdekke eventuelle små forskjeller. Dessuten tok ikke kriteriene hensyn til potensielt viktige momenter som støtte i bakre kortikale del av lårhalsen og gjennomboring av lårbeinshodet. Bildene var heller ikke standardiserte med tanke på hofterotasjonen. Vi erfarte også at kriteriene manglet presisjon, og kappaverdien for interobservatør-reliabilitet var lavere enn for reposisjonskriteriene. Riktignok forelå det en tendens til økt andel osteosyntesesvikt hos pasientene som ble gitt en lavere poengsum for plasseringen av osteosyntesematerialet, men denne økningen var ikke statistisk signifikant. Dette er i motsetning til enkelte arbeider som har vist at plasseringen av osteosyntesematerialet har hatt betydning for progno$\operatorname{sen}(21,22)$.

Da vi så på operasjonstidspunktets betydning for utfallet av osteosyntesen, fant vi en signifikant økt risiko for forsinket tilheling hos pasienter operert mer enn 48 timer etter skaden. Årsaken kan være at de lokale sirkulasjonsforholdene i lårhalsområdet og lårbeinshodet best ivaretas ved rask reposisjon og stabilisering. I henhold til vårt materiale bør derfor pasienter som behandles med lukket reposisjon og osteosyntese opereres innen 48 timer da det også er vist at kort tid mellom skade og operasjon reduserer risikoen for perioperative komplikasjoner (23-26). Samtidig er det viktig å understreke at vi ikke har sett på andre faktorer som kan være av betydning, som komorbiditet, demens og funksjonsnivå. Dette er faktorer som dessuten kan ha vært skjevt fordelt mellom pasientene operert før og etter 48 timer. Vi har heller ikke sett på om det kan foreligge noen generell sammenheng mellom risikoen for osteosyntesesvikt og tid fra skade
Tabell 1 Median alder, kjønnssammensetning, osteosyntesesvikt og mortalitet hos de inkluderte pasientene. Absolutte tall (\%)

\begin{tabular}{|c|c|c|c|}
\hline & $\begin{array}{l}\text { Udislokerte brudd } \\
\text { (Garden I-II) }\end{array}$ & $\begin{array}{l}\text { Dislokerte brudd } \\
\text { (Garden III-IV] }\end{array}$ & Totalt \\
\hline Antall & 117 & 220 & 337 \\
\hline Median alder & 81 & 82 & 82 \\
\hline Kvinner & $89(76,1)$ & $179(81,4)$ & $268(79,5)$ \\
\hline $\begin{array}{l}\text { Osteosyntesesvikt } \\
\text { Fiksasjonssvikt } \\
\text { Manglende tilheling } \\
\text { Caputnekrose }\end{array}$ & $\begin{aligned} 12 & (10,3) \\
3 & (2,6) \\
6 & (5,1) \\
3 & (2,6)\end{aligned}$ & $\begin{array}{c}59(26,8) \\
34(15,5) \\
21(9,5) \\
4(1,8)\end{array}$ & $\begin{array}{l}71(21,1) \\
37(11,0) \\
27(8,0) \\
7(2,1)\end{array}$ \\
\hline $\begin{array}{l}\text { Mortalitet } \\
1 \mathrm{md} . \\
3 \mathrm{a} \text {. }\end{array}$ & $\begin{array}{c}4(3,4) \\
52(44,4)\end{array}$ & $\begin{array}{l}12(5,5) \\
96(43,6)\end{array}$ & $\begin{array}{c}16(4,7) \\
148(43,9)\end{array}$ \\
\hline
\end{tabular}

Tabell 2 Osteosyntesesvikt i antall fordelt på poengsummen som er gitt for reposisjonen av bruddet. Oddsforholdet (OR) beskriver oddsen for at en reposisjon som er gitt 5 eller færre poeng ender med osteosyntesesvikt sammenliknet med 6 poeng

\begin{tabular}{lcccc}
$\begin{array}{l}\text { Poengsum for } \\
\text { reposisjon av } \\
\text { bruddet }\end{array}$ & Antall & $\begin{array}{c}\text { Udislokerte brudd med } \\
\text { osteosyntesesvikt } \\
(\mathrm{n}=12)\end{array}$ & \multicolumn{2}{c}{$\begin{array}{c}\text { Dislokerte brudd med } \\
\text { osteosyntesesvikt } \\
(\mathrm{n}=59)\end{array}$} \\
\hline 6 & 11 & OR $(95 \% \mathrm{KI})$ & Antall & OR (95\% KI) \\
\hline 5 & 0 & - & 23 & Referanse \\
\hline 4 & 1 & $1,6(0,17-15,2)$ & 17 & $2,1(1,0-4,3)$ \\
\hline 3 & 0 & - & 5 & $4,9(1,7-9,2)$ \\
\hline
\end{tabular}

Tabell 3 Osteosyntesesvikt i antall fordelt på poengsummen som er gitt for plasseringen av osteosyntesematerialet. Oddsforholdet (OR) beskriver oddsen for at en plassering som er gitt 5 eller færre poeng ender med osteosyntesesvikt sammenliknet med 6 poeng

\begin{tabular}{|c|c|c|c|c|}
\hline \multirow{2}{*}{$\begin{array}{l}\text { Poengsum for } \\
\text { plassering av } \\
\text { osteosyntesematerialet }\end{array}$} & \multicolumn{2}{|c|}{$\begin{array}{l}\text { Udislokerte brudd med } \\
\text { osteosyntesesvikt } \\
\qquad(\mathrm{n}=12)\end{array}$} & \multicolumn{2}{|c|}{$\begin{array}{l}\text { Dislokerte brudd med } \\
\text { osteosyntesesvikt } \\
\qquad(n=59)\end{array}$} \\
\hline & Antall & OR (95\% KI) & Antall & OR $(95 \% \mathrm{KI})$ \\
\hline 6 & 2 & Referanse & 8 & Referanse \\
\hline 5 & 2 & $0,9(0,1-6,8)$ & 16 & $1,1(0,4-2,9)$ \\
\hline 4 & 5 & $2,1(0,4-11,4)$ & 18 & $2,0(0,8-5,2)$ \\
\hline$\leq 3$ & 3 & $2,7(0,4-18,0)$ & 17 & $1,5(0,6-4,0)$ \\
\hline
\end{tabular}

Tabell 4 Osteosyntesesvikt i antall hos pasienter operert innen eller etter 48 timer

\begin{tabular}{|c|c|c|c|c|c|c|}
\hline & \multicolumn{3}{|c|}{$\begin{array}{l}\text { Udislokerte brudd } \\
\qquad(\mathrm{n}=117)\end{array}$} & \multicolumn{3}{|c|}{$\begin{array}{l}\text { Dislokerte brudd } \\
\qquad(\mathrm{n}=220)\end{array}$} \\
\hline & $\begin{array}{l}<48 \text { timer } \\
(n=92)\end{array}$ & $\begin{array}{l}>48 \text { timer } \\
(n=25)\end{array}$ & P-verdi & $\begin{array}{l}<48 \text { timer } \\
(n=200)\end{array}$ & $\begin{array}{l}>48 \text { timer } \\
(\mathrm{n}=20)\end{array}$ & P-verdi \\
\hline Totalt antall svikt & $9(9,8)$ & $3(12,0)$ & 0,72 & $50(25,0)$ & $9(45,0)$ & 0,054 \\
\hline Fiksasjonssvikt & $3(3,3)$ & 0 & 0,36 & $31(15,5)$ & $3(15,0)$ & 0,95 \\
\hline Manglende tilheling & $4(4,3)$ & $2(8,0)$ & 0,46 & $16(8,0)$ & $5(25,0)$ & 0,014 \\
\hline Caputnekrose & $2(2,2)$ & $1(4,0)$ & 0,61 & $3(1,5)$ & $1(5,0)$ & 0,26 \\
\hline
\end{tabular}




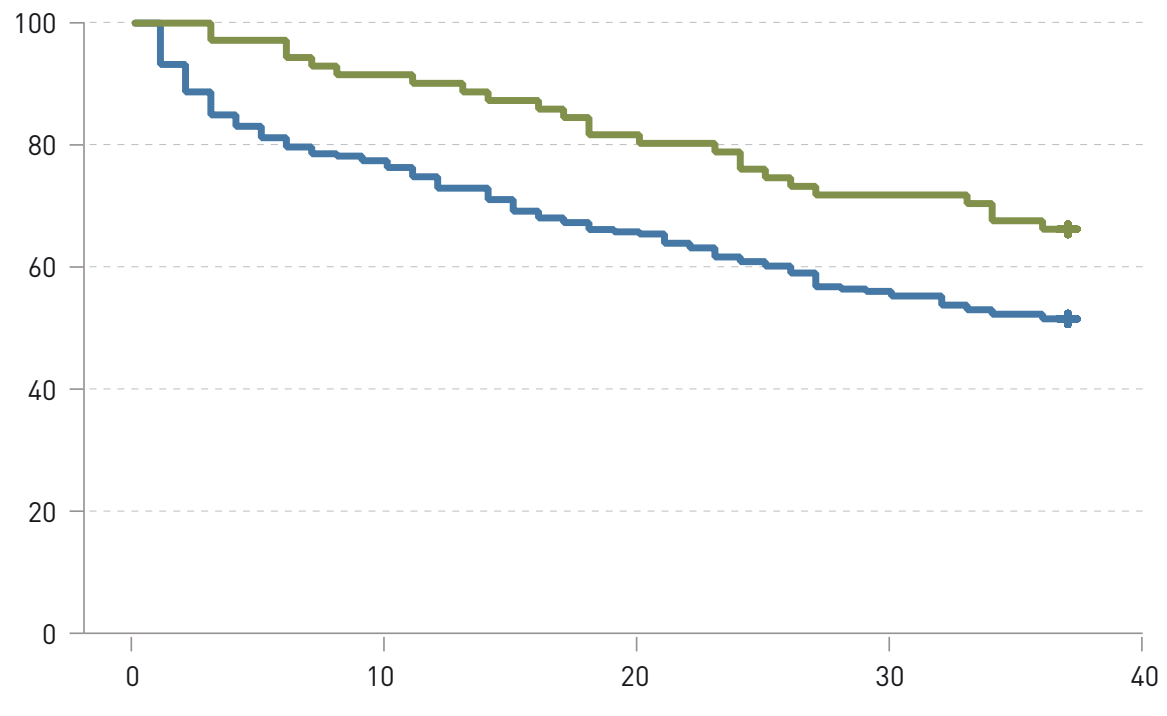

Overlevelse etter operasjon (md.)

Figur 1 Kaplan-Meier-kurver som viser overlevelse etter osteosyntese av lårhalsbrudd hos pasienter med og uten kjent svikt av osteosyntesen

til operasjon, noe tidligere arbeider har gitt holdepunkter for (27).

Osteosyntese medfører mer langvarig rehabilitering og økt risiko for reoperasjon enn protesekirurgi. Dette reiser spørsmålet om dårligere funksjon og manglende mobilisering hos pasienter med osteosyntesesvikt fører til høyere mortalitet. Vi fant imidlertid ingen økt mortalitet hos pasienter som fikk utført dårligere reposisjon eller hos pasienter som ble operert mer enn 48 timer etter skaden. Dette kan tyde på at det foreligger andre faktorer som er av større betydning. Lavere mortalitet hos pasienter som fikk konstatert osteosyntesesvikt skyldes sannsynligvis at enkelte døde før osteosyntesen sviktet, men det kan også bero på manglende oppfølging av de dårligste pasientene. Dessuten kan det være slik at de mest vitale pasientene utsetter osteosyntesen for en større belastning. Selv om økt risiko for osteosyntesesvikt ikke medførte en høyere mortalitet $i$ vårt materiale, vil pasientenes livskvalitet $i$ vesentlig grad være betinget av smertefrihet og en god gangfunksjon. Dette understreker igjen behovet for tett og god oppfølging av en sårbar pasientgruppe som etter vår erfaring $\mathrm{i}$ liten grad stiller krav til helsetjenestene.

\section{Konklusjon}

Vi har forsøkt å avdekke behandlingsrelaterte faktorer som øker risikoen for osteosyntesesvikt hos pasienter med mediale lårhalsbrudd. Vi viser at operasjon mer enn 48 timer etter skadetidspunktet gir høyere risiko for osteosyntesesvikt hos pasienter med dislokerte lårhalsbrudd. I henhold til vårt materiale bør derfor denne pasientgruppen opereres innen 48 timer med mindre det foreligger andre hensyn eller medisinske kontraindikasjoner. Vi viser også at risikoen for osteosyn- tesesvikt hos pasienter med dislokerte mediale lårhalsbrudd øker når kvaliteten på reposisjonen er dårlig. Dette medfører at man bør oppnå best mulig reposisjon $i$ to plan dersom man velger å behandle disse pasientene med lukket reposisjon og osteosyntese. Hvis man ikke oppnår en god reposisjon, bør man vurdere å konvertere til artroplastikk.

\section{Sigurd Erik Hoelsbrekken (f. 1975)}

er ph.d. og lege i spesialisering ved Ortopedisk avdeling, Akershus universitetssykehus.

Forfatter har fylt ut ICMJE-skjemaet og oppgir ingen interessekonflikter.

\section{Jan-Henrik Opsahl (f. 1978)}

er lege i spesialisering ved Radiologisk avdeling, Drammen sykehus. Han er også utdannet fysioterapeut, og har styreverv i Oslo og Akershus idrettsmedisinske faggruppe.

Forfatter har fylt ut ICMJE-skjemaet og oppgir ingen interessekonflikter.

\section{Morten Stiris (f. 1949)}

er spesialist i medisinsk radiologi med spesiell erfaring i muskel- og skjelettdiagnostikk. Han var ansatt ved Radiologisk avdeling, Aker sykehus 1980-2010, er nå medisinsk sjef ved Unilabs røntgen, avdeling. Bryn, Oslo.

Forfatter har fylt ut ICMJE-skjemaet og oppgir ingen interessekonflikter.

\section{Øyvind Paulsrud (f. 1954)}

er spesialist i generell og i ortopedisk kirurgi. Han er overlege ved Ortopedisk avdeling, Oslo universitetssykehus, Aker.

Forfatter har fylt ut ICMJE-skjemaet og oppgir følgende interessekonflikter: Han har mottatt reisestøtte fra Synthes og Zimmer.

\section{Knut Strømsøe (f. 1946)}

er spesialist i generell og i ortopedisk kirurgi og var tidligere avdelingsleder ved Ortopedisk avdeling, Aker universitetssykehus. Han er professor emeritus, Universitetet i Oslo. Han har vært spesielt opptatt av kirurgisk patofysiologi og bruddkirurgi gjennom 40 år, de senere 15 årene særlig av geriatrisk traumatologi. Forfatter har fylt ut ICMJE-skjemaet og oppgir ingen interessekonflikter.

\section{Litteratur}

1. Opsahl JH, Stiris M, Paulsrud $\emptyset$ et al. Behandlingsrelaterte risikofaktorer for osteosyntesesvikt ved lukket reposisjon og osteosyntese av mediale lårhalsbrudd. Hovedoppgave. Oslo: Det medisinske fakultet, Universitetet i Oslo, 2009.

2. Nasjonalt hoftebruddregister 2010. Bergen Helse-Bergen HF, Ortopedisk klinikk, Haukeland universitetssjukehus, 2010.

3. Rogmark C, Johnell O. Primary arthroplasty is better than internal fixation of displaced femoral neck fractures: a meta-analysis of 14 randomized studies with 2,289 patients. Acta Orthop 2006; 77 359-67.

4. Frihagen F, Nordsletten L, Madsen JE. Hemiarthroplasty or internal fixation for intracapsular displaced femoral neck fractures: randomised controlled trial. BMJ 2007; 335: 1251-4.

5. Lu-Yao GL, Keller RB, Littenberg B et al. Outcomes after displaced fractures of the femoral neck. A meta-analysis of one hundred and six published reports. J Bone Joint Surg Am 1994; 76: 15-25.

6. Parker MJ. Garden grading of intracapsular fractures: meaningful or misleading? Injury 1993; 24 $241-2$

7. Alberts KA, Dahlborn M, Ringertz H. Sequential scintimetry in prediction of healing rate after femoral neck fracture. Arch Orthop Trauma Surg 1987; 106: 168-72.

8. Lykke N, Lerud PJ, Strømsøe K et al. Fixation of fractures of the femoral neck. A prospective, randomised trial of three Ullevaal hip screws versus two Hansson hook-pins. J Bone Joint Surg Br 2003; 85: 426-30. 
9. Elmerson S, Sjöstedt A, Zetterberg C. Fixation of femoral neck fracture. A randomized 2-year follow-up study of hook pins and sliding screw plate in 222 patients. Acta Orthop Scand 1995; 66: 507-10.

10. Holmberg S, Mattsson P, Dahlborn M et al. Fixation of 220 femoral neck fractures. A prospective comparison of the Rydell nail and the LIH hook pins. Acta Orthop Scand 1990; 61: 154-7.

11. Strömqvist B, Nilsson LT, Thorngren KG. Femoral neck fracture fixation with hook-pins. 2-year results and learning curve in 626 prospective cases. Acta Orthop Scand 1992; 63: 282-7.

12. Barnes R, Brown JT, Garden RS et al. Subcapital fractures of the femur. A prospective review. J Bone Joint Surg Br 1976; 58: 2-24.

13. Garden RS. Malreduction and avascular necrosis in subcapital fractures of the femur. J Bone Joint Surg Br 1971: 53: 183-97.

14. Alho A, Benterud JG, Müller $C$ et al. Prediction of fixation failure in femoral neck fractures. Comminution and avascularity studied in 40 patients. Acta Orthop Scand 1993; 64: 408-10.

15. Alho A, Benterud JG, Rønningen $\mathrm{H}$ et al. Prediction of disturbed healing in femoral neck fracture. Radiographic analysis of 149 cases. Acta Orthop Scand 1992; 63: 639-44.

16. Alho A, Benterud JG, Solovieva S. Internally fixed femoral neck fractures. Early prediction of failure in 203 elderly patients with displaced fractures. Acta Orthop Scand 1999; 70: 141-4.

17. Weinrobe M, Stankewich CJ, Mueller B et al. Predicting the mechanical outcome of femoral neck fractures fixed with cancellous screws: an in vivo study. J Orthop Trauma 1998; 12: 27-36, discussion 36-7.

18. Bjørgul K, Reikerås 0 . Low interobserver reliability of radiographic signs predicting healing disturbance in displaced intracapsular fracture of the femoral neck. Acta Orthop Scand 2002; 73 : $307-10$.

19. Karanicolas PJ, Bhandari M, Walter SD et al. Interobserver reliability of classification systems to rate the quality of femoral neck fracture reduction. J Orthop Trauma 2009; 23: 408-12.

20. Tötterman A, Walløe A, Nordsletten L. Interpreting preoperative radiographs in displaced femoral neck fractures: observer variability in evaluating signs of poor outcome. Arch Orthop Trauma Surg 2007; 127: 185-9.

21. Lindequist $S$, Törnkvist $H$. Quality of reduction and cortical screw support in femoral neck fractures. An analysis of 72 fractures with a new computerized measuring method. J Orthop Trauma 1995; 9. 215-21.

22. von Bahr V, Syk B, Walheim G. Osteosynthesis of femoral neck fracture using screws. Acta Chir Scand 1974; 140: 277-82.

23. Zuckerman JD, Skovron ML, Koval KJ et al. Postoperative complications and mortality associated with operative delay in older patients who have a fracture of the hip. J Bone Joint Surg Am 1995; 77: $1551-6$

24. Orosz GM, Magaziner J, Hannan EL et al. Association of timing of surgery for hip fracture and patient outcomes. JAMA 2004; 291: 1738-43.

25. Weller I, Wai EK, Jaglal $S$ et al. The effect of hospital type and surgical delay on mortality after surgery for hip fracture. J Bone Joint Surg Br 2005; 87: $361-6$

26. Juliebø V, Bjøro K, Krogseth M et al. Risk factors for preoperative and postoperative delirium in elderly patients with hip fracture. J Am Geriatr Soc 2009; 57: 1354-61.

27. Massie WK. Treatment of femoral neck fractures emphasizing long term follow-up observations on aseptic necrosis. Clin Orthop Relat Res 1973; 92 $16-62$

Mottatt 21.6. 2011, første revisjon innsendt 1.8. 2011, godkjent 16.2. 2012. Medisinsk redaktør Are Brean. 